\title{
A Study on the Online School Violence of Teenagers in Cyberspace
}

\author{
Won-Hyun $\mathrm{So}^{1}$, Ha-Kyun Kim² \\ ${ }^{1}$ Professor, 13455 Graduate School of Korean Studies, The Academy of Korean Studies, 323, Haogae- \\ ro, Republic of Korea,whs@aks.ac.kr \\ ${ }^{2}$ Professor, 48513 Division of Business, Pukyong National Univ. 45, Yongso-ro, Nam-Gu. Busan, \\ Korea,kimhk@pknu.ac.kr \\ Corresponding author: Ha-kyun Kim
}

\begin{abstract}
Adolescents may deliberately experience violence from someone they know, but they may also experience violence spontaneously from someone they do not know. Online, the peculiarity that people you know and people you don't know are connected together enhances various damage experiences. In this respect, it is important to examine the causes of cyber violence by dividing the types into targets for specific people and targets for unspecified people. Cyberbullying is a different concept from traditional offline school violence, but it is clear that it has a theoretical connection. Cyberbullying differs from physical violence because the violence (harassment, insults, and stalking) occurs in cyberspace. Therefore, it can happen anytime and anywhere without being limited by time and space. While they are closely related, Cyberbullying can be fatal to young adolescents and cause profound psychological distress. The survey analysis used SPSS 22.0 for basic statistics and Smart PLS 2.0 for hypothesis testing. This study focuses on analyzing the relationship between school violence, negative emotions, and cyberbullying. The factors that determine cyberbullying are harassment, insults and stalking. A summary of the research findings is as follows. First, school violence has a significant impact on negative emotions. Second, negative emotions significantly affect harassment. Third, negative emotions significantly affect insults. Fourth, negative emotions significantly affect the stalking. Therefore, given that anger searches affect cyberbullying searches, it is believed that the development of programs that can control tension and anger with healthy life practices will be necessary.
\end{abstract}

Keywords: : School Violence, Negative Emotions, Harassment, Insults, Stalking

\section{Introduction}

The problem of violence in schools did not appear suddenly in recent years, and has gotten intensive in society. This study pays attention to the fact that the type of violence is changing from physical violence done offline to verbal and psychological violence online such as on social media. In fact, statistical surveys that prove that offline violence is evolving into cyber violence are easy to find. The problem is that in the case of verbal and mental violence occurring in cyberspace, rather than the physical violence in the past, negative emotional states such as anger and frustration, decreased selfesteem, and embarrassment cause the violence. It is said that it causes more serious consequences, such as fatal damage to the mental health of the victim.

School violence continues to occur despite efforts by the government and educational authorities, to

Received: August 22, 2020; $1^{\text {st }}$ Review Result: October 06, 2020; $2^{\text {nd }}$ Review Result: November 19, 2020 Accepted: December 28, 2020 
eradicate it. As for the ratio by type of violence, verbal violence, bullying, and stalking appeared in that order. It is worth noting that the percentage of cyberbullying that occurs online outpaced offline violence. The frequency of communication using SNS is increasing due to the development of the Internet and increase in the use of smartphones. Online violence is as severe as offline violence such as traditional verbal and physical violence. With the rapid development of technology, the importance of the Internet is gradually increasing, and the damage rate of online school violence is expected to continue to increase. In the case of adolescents, the relationships they have in the school environment affect their daily life, including school and home life. Violence in schools does not remain fragmentary, but continues to exert its influence online. Offline and online school violence share a similar overlapping pattern.

In a survey of 7,000 students conducted by the National Institutes of Health (NIH), it was reported that adolescents felt more of a sense of alienation, loss of humanity, and helplessness due to cyber violence than actual violence. The results of this survey can be considered to have empirically suggested that cyber violence is more harmful than offline violence[1].

Cyberbullying is a variety of violence (harassment insults, stalking) in cyberspace that is different from realistic violence. Because it occurs in cyberspace, it is different from physical violence, and happens regardless of time and space. In recent years, the influence of cyberbullying has been even worse than offline violence. However, offline and online violence are closely related. Cyberbullying can happen constantly. Thus, cyberbullying of a person can deeply injure them, and can be fatal.

Among the participants in online activities using smart devices, violence by cyberbullying was ranked fourth after verbal abuse, bullying and physical violence. A questionnaire about the places where school violence is conducted was given to middle and high school students and included items such as virtual devices, smart devices and the Internet. This shows the seriousness of the cyberbullying damage of middle and high school students. Assuming Korea's high global market share of smart devices, cyberbullying is more serious. It is rapidly expanding among young people with the development of smart devices. Cyberbullying is a different concept from traditional school violence, but it is clear that it has a theoretical connection. Cyberbullying is caused by psychological anxiety, which is environmentally related to offline environmental factors such as school and home[2]. As a detailed factor of schools, it can be divided into school life and school violence.

Full-scale research on cyberbullying has only begun recently and is still at a relatively early stage. To date, most of the studies on cyberbullying have dealt with the psychological distress of adolescents. The focus is on identifying the causes of this distress such as depression, sexual insufficiency and the interpersonal relationships of cyberbullying victims. It is important to identify the causes of cyberbullying and the psychological distress of the victims. However, it is also important to study how negative emotions from school violence affect cyberbullying, and it is very important to prevent its recurrence.

This study divided the causes of cyberbullying into school violence and negative emotions. It empirically analyzed whether school violence affects cyberbullying (bullying, insults, stalking) through anger. In order to test the relationship between school violence, negative emotions and cyberbullying factors, the parcel least square (PLS) method was used.

\section{Theoretical Background}

\subsection{School Violence Online}

Types of school violence include offline violence, such as traditional verbal and physical violence, and online violence that has emerged as a result of technological advances. School violence was categorized into direct and indirect violence. In detail, it was divided into four types: physical 
violence, verbal violence, relational violence, and cyber violence. Physical and verbal violence are categorized into direct violence, and relational and cyber violence are categorized into indirect violence. Cyber violence includes online gossip and derogation, and the dissemination of personal information. School violence defines the types of violent behavior differently according to the research purpose, and there is a difference in the actual incidence rate.

In the past, the role types of school violence showed distinct categories such as persecution, damage, consent, and bystander. In recent years, the number of aggressive victims has increased as the types of school violence overlap due to the increase in the use of the Internet and SNS. On- and offline aggressive victims are groups that are also victims of online and offline school violence. It is known that the level of anxiety and depression is also the highest, while being rejected the most by peers[3].

In fact, various previous studies reported the seriousness of the youth of violence victims and emphasized the importance of prevention. As a representative empirical study, this study was conducted with a cohort of 2,232 children to analyze the effects of school violence on younger children[1]. The damage from school violence experienced in the lower grades of elementary school caused maladjustment symptoms that were more severe than the damage after that. Physical violence experienced in the lower grades affected drinking, smoking, and aggression, and relational violence was verified to affect substance abuse, raising risks. As a result of school violence, psychological problems such as low self-esteem and depression, school maladjustment, decline in academic achievement, and increased suicide risk are noted[4].

Online school violence among teenagers is an expanded form of offline school violence in terms of time and space. It is a dynamic group interaction and social phenomenon involving all classes. The damage from offline school violence is closely related to the prediction of online school violence. It is also subjective psychological discomfort such as depression and aggression, low empathy ability and weak self-concept of aggressive victims on- and offline. This psychological discomfort does not end with a psychological defect in the developmental period, but becomes an obstacle to normal adult development. There is a need for a comparative study of the psychological characteristics of online and offline aggressive victims whose roles are overlapping beyond the dichotomy of the perpetrator victim.

As the definition of cyber violence varies from researcher to researcher, the types of cyber violence also differ. In general, the types of cyber violence include cyberbullying, cyber offensive language, flaming, cyber sexual assault, cyber defamation, outing and cyber stalking[5]. There are various definitions and explanations for cyberbullying, and a lot of research has recently been conducted on specific types of school violence[6]. Cyberbullying is defined as another type of school violence using social media and information devices with deliberate and repetitive behavior. Cyberbullying generally occurs frequently in adolescents. It is very difficult to detect and monitor the unique forms of cyberbullying that occur in cyberspace. The development of information and communications technologies (ICT) has shown another form of an invisible problem over the existing forms of school violence[7]. For this reason, cyberbullying is used as a means of harassing or abusing classmates and friends among adults as well as teenagers.

School violence on line is creating a new problem in schools, but it is not yet mature. The purpose of this study is to provide information that school can refer to in order to successfully solve the school violence and reduce resistance of cyberbullying. In this study, the characteristics of the cyberbullying were divided into harassment, insult, and stalking. This is a study that empirically analyzes how the school violence affects the characteristic factors of the cyberbullying. The structural equation model (PLS 2.0) was adopted to test the relationship of the factors described above. SPSS 12.0 is used for basic statistics. 


\subsection{Negative Emotions}

Prior studies focusing on the relationship between negative emotions and product purchase tended to recognize various aspects of negative emotions as a single dimension. Recent studies have shown the effect of distinct negative emotions such as sadness and anger. Angry people have a strong tendency to believe that they have control over what will happen in the future. People have a high level of confidence in their own judgment. Anger causes people to rely on heuristics to process information, and temporary anger increases the propensity to believe that people other than themselves are responsible for future events. It is known that the negative emotions experienced by consumers in the process of using information technology affect the decision-making process for "approach and being flexible" or "avoidance and being rigid". When consumers evaluate or purchase a product, if there is a difference between their thoughts and reality about the product, they will experience conflicts and confusion and have difficulty in purchasing. Confused consumers have negative feelings about the product. Therefore, various emotions such as anger, anxiety, impatience, nervousness, and self-doubt are included in negative emotions.

In the process of constructing risk-related behavioral intentions for ordinary people, emotional reactions play an important mediating role. The relationship between feelings for risk messages and cognitive triggers is not yet clear. However, according to the "emotional heuristic" and "the theory of cognitive evaluation of emotions," emotions act as mediators. According to the basic concept of emotion, emotions evoke people's thoughts in the process of recognizing and interpreting uncertain and complex situations. These influences affect social judgment in the future. According to 'Theory of Emotions as Information', emotions function as information about a specific situation. It influences subsequent motives, beliefs, and attitudes. When these discussions are put together, it is possible that emotions induced by a specific stimulus act as a path of emotions in terms of their influence. Cognition triggered unconsciously, forms a certain attitude and leads to motivational action.

As the information processing becomes more complex, it is likely to experience cognitive complexity in turn, leading to confusions with negative emotions such as frustration, anger, and irritation. When people assess their environment confusing and not secure, leading more rigid decision making with psychological stress. Negative behavioral reactions were divided into two dimensions of "approach" and "avoidance," and the influence of perceived risk from personal information leakage on negative emotions and negative behavioral reactions was examined. Negative emotions are a major component of cyberbullying and are associated with misconduct and crime. This is caused by the failure of goal achievement due to the unstable factors. It leads to frustration, disappointment, anger, dissatisfaction, and negative emotions. Newly adapted groups in the cyber environment suggest various actions to adapt to the new environment of cyberspace. The harmful environment of cyberspace causes negative emotions in the groups adapting to it[8]. Such negative emotions are manifested externally. The tension in the new environment creates negative emotions, which increase cyberbullying. Measuring negative emotions In psychological terms varies among scholars studying it.

The experience of school violence, abusive behavior, and academic stress were investigated as the main causes in predicting cyberbullying. It was found that one of the important internal factors that can influence the relationship between stress and cyberbullying behavior is the ability to control negative emotions[9]. The results of the analysis showed that the experience of school violence, abuse and academic stress are significantly associated with cyberbullying. And the relationship between these factors and cyberbullying is shown to be mediated by the regulation of negative emotions of adolescents. 


\subsection{Cyberbullying}

Cyberbullying is included in the Act on Prevention and Countermeasures against School Violence. It is the act of students using a communication device such as the Internet or a mobile phone to continuously and repeatedly psychologically attack or disseminate personal or false information related to a specific student.

Early research on cyberbullying, like research on other topics, focused on defining the concept or establishing the types of cyberbullying[10]. As a specific type of school violence, it has recently attracted the attention of many researchers. In addition, cyberbullying was defined as a type of school violence that used computers, cell phones, and other electronic devices as deliberate and repetitive behaviors.

It is necessary to examine the types of cyber violence damage by dividing them into damage caused by a specific person and damage caused by an unspecified person. Currently, juvenile cyber violence overlaps both types, so it is necessary to identify the cause by classifying the types. In particular, adolescent cyber violence needs to be understood from multiple perspectives. When the individual and environmental characteristics according to the type of damage are more specifically identified, practical measures can be prepared. From this point of view, the damage caused by people you know online needs to be understood in a relational context offline. The more you experience difficulties with someone close to you, the more negative emotions become latent. They experience damage because they are more vulnerable to online emotions[11]. The experience of damage from an unknown person is an improvised experience of violence during online activities, and the damage is experienced more due to a lack of skills in interpersonal relationships and response methods[12]. However, in the studies so far, it is difficult to clearly understand the cause of the damage because the causal relationship of the factors causing the damage is not clear.

Violence by a person is defined as deliberate and repetitive behavior by individuals and groups with the intent to harm others. It is different from violence against unspecified people in that if you are bullied by a specific person, you will experience more wounds and continue suffering. In addition, violence by an unspecified person is an act of violence that occurs accidentally while using the Internet, and it can be said that violence occurs spontaneously without any special reason.

There are various types of cyberbullying, but a maximum of 12 have been classified. Cyberbullying exists in various areas from slander and insults to identity theft and cyber sexual violence. Offline bullying and cyberbullying are closely related. A student who experiences bullying in school is likely to be an assaulter in the virtual space by resisting his damage[13]. The most commonly used submeasurement variables of cyberbullying were insults, harassment and stalking. These results are influential in the order of insults, harassment and stalking. Among cybercrimes, sexual violence such as sneak shots, stalking, and distribution of cyber pornography is increasing. It continues to emerge as a general social problem, not only in cyberspace[14]. The results of research on cyber sexual violence showed that women in cyber space suffered from demands for sex, sexual swearing, sexual expressions, online stalking, and real sex. Recently, research related to cyberbullying has been increasing rapidly. The reason for this is that suicides by teenagers related to cyberbullying is becoming a social problem. In amendments to the Act on the Prevention and Countermeasures of School Violence, amendments proposing cyberbullying as school violence have been promulgated. This is due to the importance of the issue[15].

\section{Research Design}

\subsection{Research Model}


Interviewees feel that cyberbullying is more serious than violence in the offline space. The main reason for this is that in an anonymous situation, you can constantly harass your friends without being limited by space. In the case of cyberbullying, ethical issues should be prioritized. Questionnaires were used for hypothesis testing. The survey period lasted for one month in March 2018. The model of the study focuses on analyzing the relationship between school violence and negative emotions and cyberbullying in cyberspace. In the research model, cyberbullying was divided into harassment, insults, and stalking. Based on the existing research, the research model is presented in [Fig. 1].

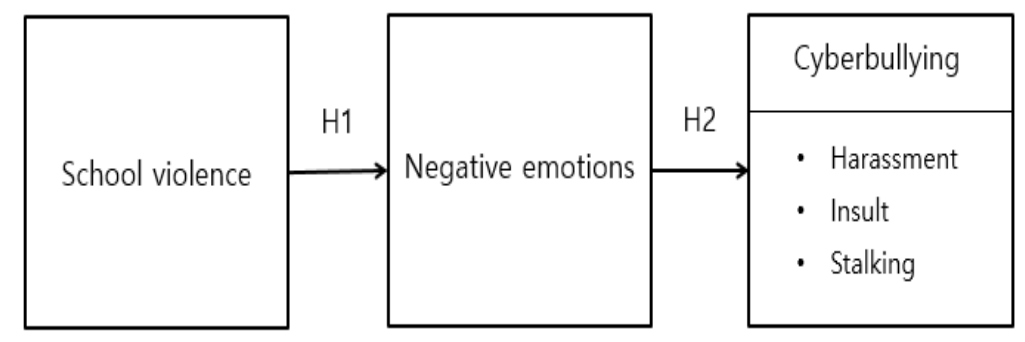

[Fig. 1] Research Model

\subsection{Research Hypotheses}

There has been much research on specific types of school violence in recent years. In particular, many studies on online school violence and cyberbullying have been conducted. Negative emotions are associated with misconduct and crime. It has been explained that a harmful environment for adolescents causes negative emotions. Therefore, a hypothesis about harmful environment of school violence was established based on the previous research.

Hypothesis H1: Online school violence will have a significant effect on negative emotions.

In general strain theory, the tension experienced by an individual in everyday life directly affects crime or misconduct. It also explains how negative emotions such as anger and stress can lead to crime or misconduct[16][17]. There are various factors in the type of cyberbullying, but this study uses bullying, insults and stalking. Hypotheses about negative emotions were established based on previous studies.

Hypothesis H2-1: Negative emotions will have a significant effect on harassment.

Hypothesis H2-2: Negative emotions will have a significant effect on insults.

Hypothesis H2-2: Negative emotions will have a significant effect on stalking.

\section{Empirical Analysis and Results}

The survey analysis used SPSS 22.0 for basic statistics and Smart PLS 2.0 for hypothesis testing. Factor loading values, Cronbach's $\alpha$, compositional reliability (C. R.) and average variance extraction index values (AVE) of each factor were examined. Factor loadings of 0.6 or more, Cronbach's $\alpha$ and compositional reliability values of 0.7 or more, and dispersion extraction index values of 0.5 or more are generally considered valid.

\subsection{Data Collection and Sample Characteristics}

A total of 320 users answered the survey, and 290 questionnaires were used for hypothesis testing, except for unfaithful responses. The survey period lasted for one month in March 2018. The basic survey statistics are as follows: $45 \%$ of respondents were male and 55\% were female. There was a relatively higher proportion of female students than male students. The mean age was 15.8 years. The distribution of middle and high school grades is as follows: $31.7 \%$ of third graders in middle school 
and $29.3 \%$ of second graders in middle school. Looking at the distribution by student, middle school students were the highest with $68.5 \%$ and high school students with $31.5 \%$.

\subsection{Data Analysis Method}

The intensive feasibility analysis of the data is shown in [Table 1]. Discriminant validity is compared with the square root of the variance extraction index value and the correlation coefficient in [Table 2].

[Table 1] Reliability and Internal Consistency

\begin{tabular}{|c|c|c|c|c|}
\hline Variable & Factor Loading & AVE & C. R. & Cronbach's $\alpha$ \\
\hline \multirow{3}{*}{ School violence } & 0.923 & \multirow{3}{*}{0.862} & \multirow{3}{*}{0.949} & \multirow{3}{*}{0.920} \\
\hline & 0.939 & & & \\
\hline & 0.926 & & & \\
\hline \multirow{3}{*}{ Negative emotions } & 0.958 & \multirow{3}{*}{0.872} & \multirow{3}{*}{0.953} & \multirow{3}{*}{0.926} \\
\hline & 0.962 & & & \\
\hline & 0.909 & & & \\
\hline \multirow{4}{*}{ Harassment } & 0.934 & \multirow{4}{*}{0.857} & \multirow{4}{*}{0.960} & \multirow{4}{*}{0.944} \\
\hline & 0.932 & & & \\
\hline & 0.928 & & & \\
\hline & 0.908 & & & \\
\hline \multirow{3}{*}{ Insults } & 0.942 & \multirow{3}{*}{0.853} & \multirow{3}{*}{0.945} & \multirow{3}{*}{0.913} \\
\hline & 0.964 & & & \\
\hline & 0.860 & & & \\
\hline \multirow{4}{*}{ Stalking } & 0.935 & \multirow{4}{*}{0.881} & \multirow{4}{*}{0.967} & \multirow{4}{*}{0.955} \\
\hline & 0.942 & & & \\
\hline & 0.947 & & & \\
\hline & 0.930 & & & \\
\hline
\end{tabular}

[Table 2] Correlation and Discriminant Validity

\begin{tabular}{|c|c|c|c|c|c|c|}
\hline Variable & AVE & 1 & 2 & 3 & 4 & 5 \\
\hline School violence & 0.862 & $\mathbf{0 . 9 2 8}$ & & & & \\
\hline Negative emotions & 0.872 & 0.453 & $\mathbf{0 . 9 3 3}$ & & & \\
\hline Harassment & 0.857 & 0.517 & 0.462 & $\mathbf{0 . 9 2 5}$ & & $\mathbf{0 . 9 2 3}$ \\
\hline Insults & 0.853 & 0.483 & 0.521 & 0.511 & 0.410 & $\mathbf{0 . 9 3 8}$ \\
\hline Stalking & 0.881 & 0.476 & 0.387 & 0.608 & & \\
\hline
\end{tabular}

\subsection{Verification of Research Model}

Smart PLS 2.0 was used to verify the structural model. The path coefficients and the coefficients of determination (R2) between the factors of the research model are presented. The coefficient of determination (R2) for negative emotions (0.205), harassment (0.213), and stalking (0.150) was middle. The coefficient of determination (R2) for insults (0.271) was high. 


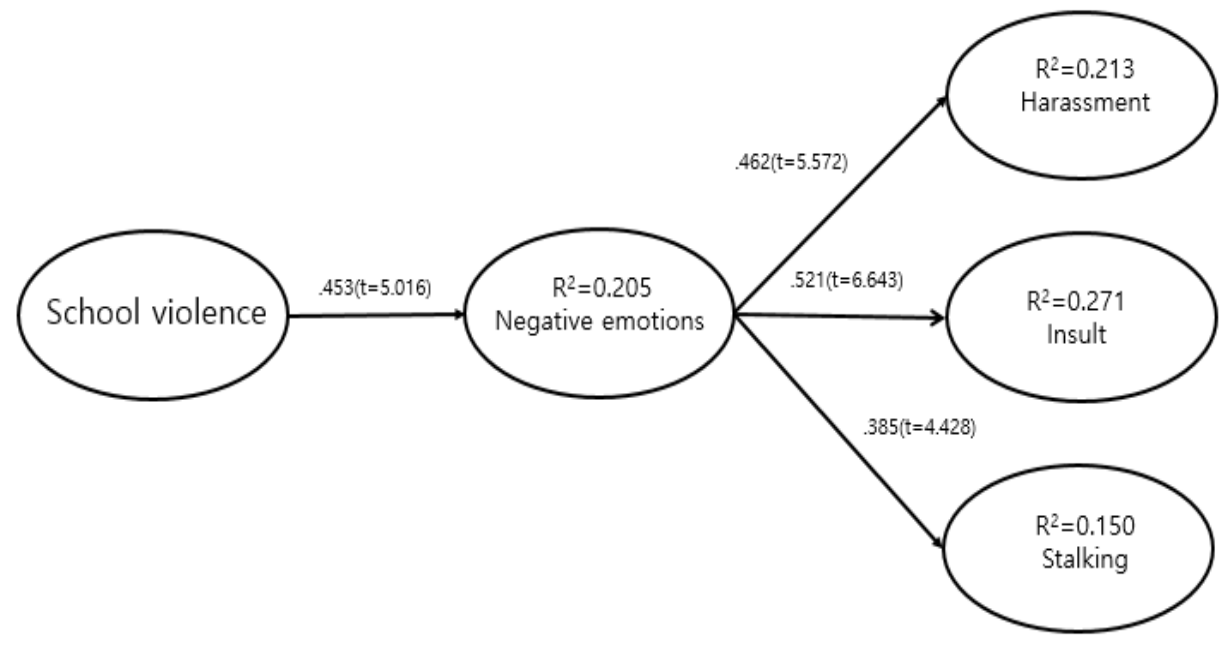

[Fig. 2] Results of Research Model

In Hypothesis H1-1, school violence and negative emotions $(\beta=0.453, \mathrm{t}=5.016, \mathrm{p}<0.05)$ have a significant effect. This is because school violence increases negative emotions. The result is that physical violence, mental violence and bullying affect anger in school violence. The more serious you do not think about school violence online, the more likely you are to exercise cyberbullying. In hypothesis $\mathrm{H} 2-1$, negative emotions and harassment $(\beta=0.462, \mathrm{t}=0.572, \mathrm{p}<0.05)$ have a significant effect. The higher the negative emotion, the worse the harassment. Online, it is thought that there is less psychological burden on harassment because of negative emotions than offline. The negative emotions and insults of hypothesis $\mathrm{H} 2-2(\beta=0.521, \mathrm{t}=6.643, \mathrm{p}<0.05)$ had a significant effect. The higher the negative emotion, the more insulting it is. The negative emotions and stalking of hypothesis H2-3 $(\beta=0.385, \mathrm{t}=4.428, \mathrm{p}<0.05)$ were found to have a significant effect. The higher the negative emotion, the more severe the stalking. Hypothesis $\mathrm{H} 2$ results in feeling less psychological guilt online than offline in bullying the other. Online school violence is considered an important factor in negative emotions in cyberbullying (harassment, insults, stalking). Negative emotions are the most important factor in general theory. In addition, research results show that anger is an important variable in cyberspace.

[Table 3] Hypotheses Testing Results

\begin{tabular}{|l|c|c|c|}
\hline \multicolumn{1}{|c|}{ Hypotheses Path } & Coefficient $(\beta)$ & $\mathrm{t}$-value & Result \\
\hline H1: School violence $\rightarrow$ Negative emotions & 0.453 & 5.016 & Accept \\
\hline H2.1: Negative emotions $\rightarrow$ Harassment & 0.462 & 5.572 & Accept \\
\hline H2.2: Negative emotions $\rightarrow$ Insults & 0.521 & 6.643 & Accept \\
\hline H2.3: Negative emotions $\rightarrow$ Stalking & 0.385 & 4.428 & Accept \\
\hline \multicolumn{2}{|c}{} \\
\hline
\end{tabular}

\section{Conclusion}

School violence has reached severe levels in middle and high schools. In addition to offline violence, online school violence has become an issue in recent years. Violence in cyberspace takes many forms. Various studies on cyberbullying have been conducted. This study empirically analyzed how school violence affects cyberbullying through negative emotions in cyberspace. Online school violence has been verified in negative emotions and cyberbullying. First, school violence had a significant effect on negative emotions. Second, negative emotions had a significant effect on 
harassment. Third, negative emotions had a significant effect on insults. Fourth, negative emotions had a significant effect on stalking.

Online school violence has been identified in empirical studies of negative emotions and cyberbullying (harassment, insults, and stalking). In order to solve the problem of cyberbullying, this study differentiated the factors of cyberbullying into harassment, insults, and stalking. However, in various aspects, efforts should be made to classify and resolve these factors. Since there are various opinions on the causes of cyberbullying, detailed research on it is also necessary. Second, negative emotions affect harassment, insults, and stalking. The solution to cyberbullying should be based on the importance of negative emotions. The higher the negative emotion, the more likely it is to conduct cyberbullying. In the existing research on adolescent assaults and school violence, anger is noted as an important factor of adolescent cyber violence and school violence[18][19]. Negative emotions are presented variously in general tension theory. This research has reaffirmed the importance of previous research on negative emotions in cyberspace.

In developed countries, the problem of cyberbullying is emerging. In particular, in more developed countries, the suspicion of cyberbullying continues to be a concern with the suicides cases of teenagers[20]. Accordingly, various educational support to prevent cyberbullying is being strengthened. The U.S. Department of Health and Human Services has created a cyberbullying prevention site that details how parents, students and school staff should behave. In the UK, education and instructions on the information environment provide detailed guidance on the seriousness and how to deal with cyberbullying. Therefore, based on the previous research confirmed through this research process, the development of appropriate countermeasures against negative emotions and environmental variables is highly suggested. First, considering that stress and negative emotions affect cyberbullying, it is necessary to establish a program that can control tension and negative emotions through the practice of healthy living. Second, according to previous studies, the lower the bond, the higher the cyberbullying abusive behavior according to family ties and school ties. In addition, the same result was observed in cases of violence or witnessed violence. This suggests that cyberbullying is importantly influenced by the surrounding environment. In addition, various studies were conducted regarding the presence of delinquent friends, social support, and friendship. In particular, it is necessary to establish healthy relationships, and research shows that the presence of a delinquent friend has the greatest influence on the behavior of cyberbullying.

Based on this study, a new model of school violence, negative emotions and cyberbullying was proposed and empirically analyzed. This paper is significant for it presents an empirical study in the situation where there are not many theoretical studies on negative emotions and cyberbullying. In addition, by recognizing negative emotions and school violence, futher damage from it can be addressed.

\section{Acknowledgments}

This work was supported by a research grant from Pukyong National University (2019).

\section{References}

[1] L. Arseneault, E. Walsh, K. Trzesniewski, R. Newcombe, A. Caspi, T. E.Moffitt, Bullying Victimization Uniquely Contributes to Adjustment Problems in Young Children: A Nationally Representative Cohort Study, The Journal of Pediatrics, (2006), Vol.118, No.1, pp.130-138.

[2] T. Anderson, B. Sturm, Cyberbullying: From Playground to Computer, Young Adult Library Services, (2007), Vol.5, No.2, pp.24-27. 
[3] S. Hinduja, J. Patchin, Offline Consequence of Online Victimization: School Violence and Delinquency, Journal of Schol Violence, (2007), Vol.6, No.3, pp.89-112.

[4] M. Janosz, I. Archambault, L. S. Pagani, S. Pascal, A. J. Morin, F. Bowen, Are There Detrimental Effects of Witnessing School Violence in Early Adolescence?, Journal of Adolescent Health, (2008), Vol.43, No.6, pp.600-608.

[5] J. Lee, B. An, A Comparative Study of Cyber School Bullying in Korea and Japan, Japanese language education, (2016), Vol.76, pp.163-181.

[6] S. Sin, A study on the Relationship of Strain and cyberbullying among Adolescents, The Journal of Social Science, (2016), Vol.23, No.1, pp.339-366.

[7] S. Cha, Review of unlicensed radio wave policy, International Journal of IT-based Social Welfare Promotion and Management, (2016), Vol.3. No.1, pp.241-246.

[8] K. R. Blevins, J. L. Sheley, F. T. CulIen. C. L. Jonson, A General Strain Theory of Prison Violence and Misconduct: an integrated model of inmate behavior, Journal of Contemporary Criminal Justice, (2010), Vol.26, No.2, pp.148-166.

[9] J. Kim, E. Norman, J. Kim, Life Stresses in Adolescents with Problematic Media Use: The Role of Anger Management in cyberbullying, Family and Family Therapy, (2017), Vol.25, No.2, pp.227-249.

[10] M. A. Campbell, Cyber Bulying: An Old Problem in a New Guise?, Australian journalof Guidance and Counseling, (2005), Vol.15, No.1, pp.68-76.

[11] J. Kim, K. R. Bhatele, Recognition using Cyberbullying in view of Semantic-Enhanced Minimized Auto-Encoder, Asia-pacific Journal of Convergent Research Interchange, (2016), Vol.2, No.4, pp.7-14.

[12] W. So, H. Kim, An Empirical Study on the Effect of the Social Norms on Assault Behavior through Cyberbullying, Asia-pacific Journal of Convergent Research Interchange, (2020), Vol.6, No.2, pp.149-158.

[13] M. L. Ybarra, K. J. Mitchell, Online Aggressor/targets, Aggressor, and Targets: a Comparison of Associated Youth Characteristics, Journal of Child Psychology and Psychiatry, (2004), Vol.45, No.7, pp.1308-1316.

[14] C. Park, Status and Measures for Cyber Sexual Violence, Proceedings of the Korean Society of Computer Information Conference, (2012), May 12-13, Seoul, Korea.

[15] Minsun Kim, Byoungduk Sohn, A Meta-analysis on the Correlation of Factors Related to Cyberbullying in Adolescents, Korean Journal of Youth Studies, (2020), Vol.27, No.11, pp.377-399.

[16] S. Son, M. Gwak, Effect of Social Entrepreneurial Environment on Entrepreneurial Activity, International Journal of IT-based Business Strategy and Management, (2018), Vol.4, No.1, pp.1-6.

[17] S. Kim, Relation between Mental Health and Suicide Resilience among University Students in South Korea, International Journal of Advanced Nursing Education and Research, (2016), Vol.1, No.1, pp.103-108.

[18] R. Agnew, Building on the Foundation of General Strain Theory: Specifying the Types of Strain Most Likely to Lead to Crime and Delinquency, Journal of research in crime and delinquency, (2001), Vol.38, No.4, pp.319-361.

[19] A. Beale, K. Hall, Cyberbullying: What School Administrators (and Parents) Can Do, The Clearing House, A Journal of Educational Strategies, Issues and Ideas (2010), Vol.81, No.1, pp.8-12.

[20] S. Son, M. Gwak, Effect of Social Entrepreneurial Environment on Entrepreneurial Activity, International Journal of IT-based Business Strategy and Management, (2018), Vol.4, No.1, pp.1-6. 